\title{
A Prospective Study on the Prevalence and Risk Factors of Poststroke Depression
}

\author{
A. De Ryck ${ }^{a, c}$ R. Brouns ${ }^{f} \quad$ E. Fransen ${ }^{\text {e }}$ M. Geurden ${ }^{c} \quad$ G. Van Gestel ${ }^{c}$ \\ I. Wilssens ${ }^{c}$ L. De Ceulaer ${ }^{c}$ P. Mariën ${ }^{c, g}$ P.P. De Deyn ${ }^{b-d}$ \\ S. Engelborghs ${ }^{b, c}$
}

${ }^{a}$ Department of Nursing and Midwifery Sciences, Faculty of Medicine and Health Sciences, and University of Antwerp, ${ }^{b}$ Laboratory of Neurochemistry and Behaviour, Institute Born-Bunge, and University of Antwerp, ' Department of Neurology, Ziekenhuis Netwerk Antwerpen (ZNA) Middelheim and Hoge Beuken, dDepartment of Health Care Sciences, Artesis University College of Antwerp, and e StatUa Center for Statistics, University of Antwerp, Antwerp, ${ }^{\mathrm{f} D e p a r t m e n t}$ of Neurology, Universitair Ziekenhuis Brussel, and ${ }^{9}$ Department of Neurolinguistics, Vrije Universiteit Brussel, Brussels, Belgium

\section{Key Words}

Stroke • Poststroke depression · Cornell Scale for Depression • Montgomery and Åsberg Depression Rating Scale

\begin{abstract}
Background and Purpose: Poststroke depression (PSD) is common. Early detection of depressive symptoms and identification of patients at risk for PSD are important as PSD negatively affects stroke outcome and costs of medical care. Therefore, the aim of this study was to determine incidence and risk factors for PSD at 3 months after stroke. Methods: We conducted a prospective, longitudinal epidemiological study aiming to determine incidence and risk factors for PSD at 1, 3, 6, 12 and 18 months poststroke. The present data analysis covers the convalescent phase of 3 months poststroke. Participants in this study were inpatients, admitted to a stroke unit with first or recurrent stroke. Demographic data and vascular risk factors were collected and patients were evaluated at baseline and 3 months poststroke for functional and cognitive deficits, stroke characteristics, stroke severity and stroke outcome. Signs and symptoms of depression were quantified by means of the Cornell Scale for Depression (CSD) and Montgomery and Åsberg Depression Rating Scale (MADRS). Significantly associated variables from univariate analysis were analyzed by using multiple linear and logistic regression methods. $\boldsymbol{R e}-$ sults: Data analysis was performed in 135 patients who completed follow-up assessments at 3 months poststroke. Depression (CSD score $\geq 8$ ) was diagnosed in $28.1 \%$ of the patients. Patients with PSD were significantly more dependent with regard to activities of daily living (ADL) and
\end{abstract}




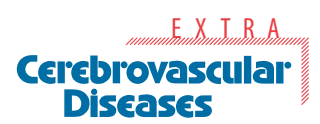

Cerebrovasc Dis Extra 2013;3:1-13

DOI: $10.1159 / 000345557$

Published online: January 26, 2013

De Ryck et al.: A Prospective Study on the Prevalence and Risk Factors of Poststroke Depression

displayed more severe physical and cognitive impairment than patients without PSD. A higher prevalence of speech and language dysfunction and apraxia were observed in patients with PSD (36.8 and 34.3\%, respectively) compared to non-depressed stroke patients ( 19.6 and $12.4 \%$; $p=0.036$ and $p=0.004$, respectively). Applying multiple linear regressions, cognitive impairment and reduced mobility as part of the Stroke Impact Scale were independently associated with PSD, as scored using CSD and MADRS ( $r^{2}=0.269$ and $r^{2}=0.474$, respectively). Conclusions: The risk of developing PSD is increased in patients with more functional and cognitive impairment, greater dependency with regard to ADL functions and with occurrence of speech and language dysfunctions and apraxia. Multiple regression models indicated that the most determining features for depression risk in the convalescent phase after stroke include reduced mobility and cognitive impairment. Further studies on risk factors for PSD are essential, given its negative impact on rehabilitation and quality of life. Identification of risk factors for PSD may allow more efficacious preventive measures and early implementation of adequate antidepressive treatment.

Copyright $\odot 2013$ S. Karger AG, Basel

\section{Introduction}

Clinically significant depressive symptoms are common following stroke [1]. The prevalence of poststroke depression (PSD) varies between 20 and 65\%, depending on the population studied, the assessment measures and the definition of depression applied $[2,3]$. Early detection of PSD is important as PSD has been negatively associated with survival, cost of medical care, compliance with therapy including rehabilitation, functional outcome, resumption of social activities and quality of life [4-7].

The pathophysiology of PSD remains to be elucidated. While some studies suggest that functional disability induced by stroke is a risk factor for PSD, others suggest a biological mechanism related to stroke-induced brain damage [8]. Still other studies suggest that risk factors for stroke also increase the risk for PSD [9]. Furthermore, cognitive symptoms and aphasia are seldom studied as risk factors for PSD [10] and are therefore included in this study.

In view of the above findings, identification of risk factors for PSD is important and helpful for early diagnosis, early and adequate treatment and to improve quality of life, both for patients and caregivers.

\section{Methods}

\section{Study Design}

This study is part of the Middelheim Interdisciplinary Stroke Study on clinical, biochemical, neuroimaging, neuropsychological and electrophysiological evaluation of patients with stroke $[11,12]$. In order to study risk factors for PSD, we conducted a prospective, longitudinal epidemiological study aiming to determine incidence and risk factors for PSD at 1 , 3, 6, 12 and 18 months poststroke. The present data analysis covers the convalescent phase of 3 months poststroke.

\section{Study Population}

Patients admitted to the stroke unit were eligible for inclusion in the study if acute stroke symptoms matched the World Health Organisation diagnostic criteria for cerebral infarction or cerebral haemorrhage. Transient ischemic attack was defined as symptoms lasting less than $1 \mathrm{~h}$ in the absence of acute cerebral ischemia on imaging [13]. 
Fig. 1. Study design.

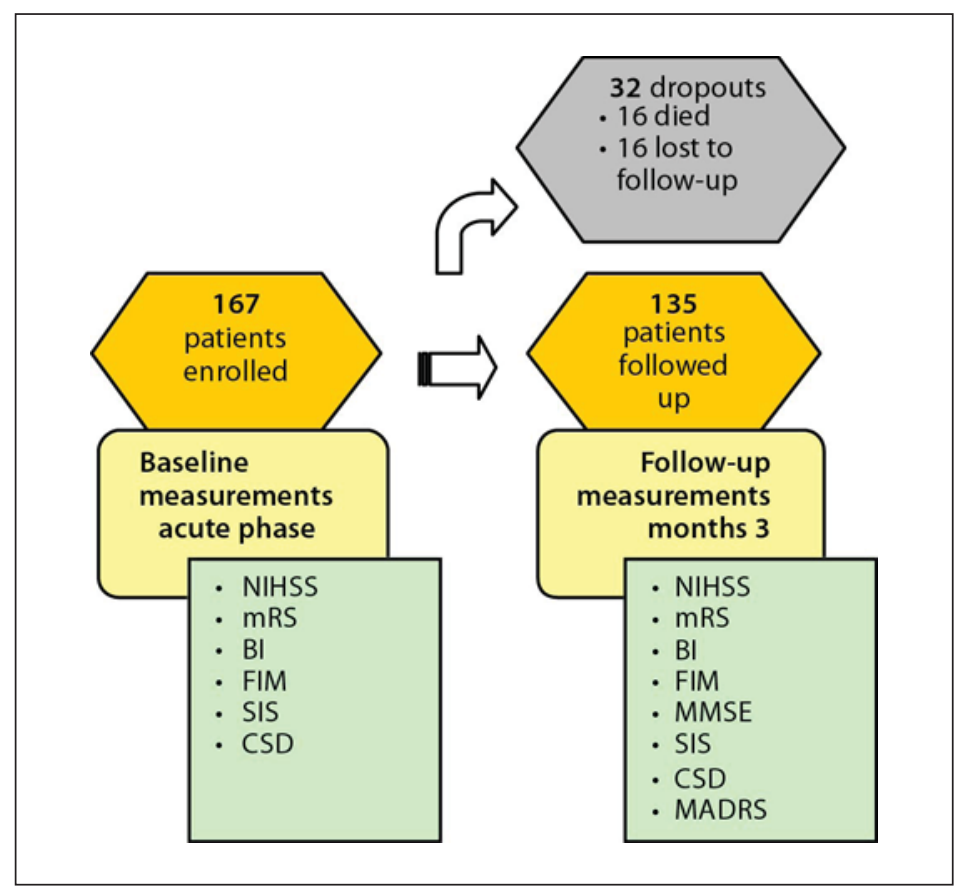

All patients were assessed within 7 days of stroke onset. Demographic data and vascular risk factors were collected by means of an interview of patients and their relatives and from the clinical records, using structured case report forms. Recorded vascular risk factors comprised previously diagnosed and treated conditions. A positive 'history of depression' was defined as the occurrence of at least one depressive episode that had required treatment with antidepressant medication or attention of a general practitioner, psychologist or psychiatrist.

At time of data analysis, 167 patients were enrolled of whom 135 were reevaluated 3 months after stroke. Sixteen patients died before the follow-up visit and 16 others were not available for follow-up (fig. 1). Three patients refused further participation for no apparent reason. One patient returned abroad and 12 patients did not show up, most likely for practical reasons deliberating their stroke severity, more functional impairment and lower level of independence at baseline.

The study was approved by the Ethics Committees of the Ziekenhuis Netwerk Antwerpen (ZNA) and the University of Antwerp. Written informed consent was obtained from each participating subject or proxy in case of aphasia, confusion or reduced consciousness. All assessments were performed by trained interviewers.

\section{Stroke Characteristics}

Diagnosis of cerebral ischemia was based on the presence of acute neurological symptoms that only could be explained by a vascular event in a specific arterial territory with a duration lasting less than $1 \mathrm{~h}$ (transient ischemic attack; $\mathrm{n}=17$ ) or with symptoms lasting more than $1 \mathrm{~h}$ [cerebral infarction $(\mathrm{n}=113)$ or haemorrhage $(\mathrm{n}=5)]$ verified by computed tomography or magnetic resonance imaging.

Stroke severity was measured by The National Institute of Health Stroke Scale (NIHSS) [14], a 15-item neurologic examination to evaluate the effect of acute cerebral ischemia on consciousness, language, neglect, visual-field loss, extraocular movement, motor strength, ataxia, dysarthria, and sensory loss. NIHSS scores range from 0 to 42 . A maximal score of 42 represents the most severe and devastating stroke. 
Lesion location on neuroimaging was grouped as left or right hemispherical or bilateral and was further subdivided according to the arterial territory involved: anterior cerebral, middle cerebral, posterior cerebral or vertebrobasilar artery.

\section{Assessment of Functional and Cognitive Deficits}

Functional impairment was measured by the Functional Independence Measure (FIM) scale [15] that includes 18 items of which 13 are motor domains on self-care, sphincter control, transfers and locomotion, and 5 cognitive domain items on communication, social interaction and cognition, each with a maximum score of 7 and a minimum score of 1 . Scores range from 18 to 126. Each level of scoring is defined. A score of 7 equals 'complete independence,' and a score of 1 equals 'complete dependence'.

The level of independence in activities of daily living (ADL) was measured with the Barthel Index (BI) [16] that measures 10 basic aspects of ADL related to self-care and mobility: control of bowel/bladder, grooming, toilet use, feeding, transfers, mobility, dressing, climbing stairs, and bathing. BI scores range from 0 to 100, lower scores indicating greater dependency.

Outcome was assessed 3 months poststroke by the modified Rankin Scale (mRS) [17]. This scale is commonly used for assessment of degree of disability or dependence in daily activities of stroke patients and consists of 6 grades, from 0 to 5 , with 0 corresponding to no symptoms and 5 corresponding to severe disability. A neuropsychological screening assessed presence or absence of confusion, aphasia (motor, sensory, global and other), dysarthria, agnosia (visual and auditory) and apraxia (ideomotor, ideational and constructive).

Cognitive functioning was assessed with the Mini-Mental State Examination (MMSE) at follow-up [18] and the cognitive domain of FIM and Stroke Impact Scale (SIS). The MMSE is an observer-rated measure of cognitive ability. It has 19 items and is scored from 0 to 30 points with a lower score indicating greater cognitive impairment. Stroke impact and quality of life before stroke were measured with the Belgian-Dutch version of the SIS (v3.0) [19]. This scale contains 47 items and assesses 5 domains (mobility or physical functions, memory and thinking ability, emotions, communication and participation in daily social activities).

\section{Assessment of Depressive Symptoms}

Symptoms of depression before stroke onset were measured using the Cornell Scale for Depression (CSD) at admission [20]. The CSD was originally developed to assess depressive symptoms in patients with dementia and can be completed through observation and informant-based questions with a relative. It thus can be applied in stroke patients with aphasia, cognitive impairment and/or reduced consciousness due to stroke. It is a 19-item scale rated on a three-point score of absent, mild/intermittent and severe. A score of $\geq 8$ suggests significant depressive symptoms [20]. This cutoff was used in the present study. Depressive symptoms were quantified during follow-up using the CSD and the Montgomery and Åsberg Depression Rating Scale (MADRS) [21]. The MADRS was developed from 65 original items from the Comprehensive Psychopathological Rating Scale and measures apparent sadness, reported sadness, inner tension, reduced sleep, reduced appetite, concentration difficulties, lassitude, and ability to feel pessimistic thoughts and suicidal thoughts, putting little emphasis on somatic symptoms. This observer-rated scale ranges from 0 to 60 , high scores reflecting more depressive symptoms.

\section{Statistical Analysis}

Data were analysed with SPSS 16.0 for windows, except for evaluation of the mRS shift which was carried out with SAS v9. For group comparisons of descriptive sample character- 
istics (demographic, neuropsychological, clinical data) the Student t test was used for continuous, normally distributed data (Kolmogorov-Smirnov test). Non-parametric statistical tests (Mann-Whitney U rank sum or Wilcoxon signed-rank test) were used for non-normal distributed data or small numbers. $\chi^{2}$ or Fisher's exact test (with expected counts $<5$ ) was used for dichotomous variables. Spearman correlations were calculated in order to test strengths of associations between CSD/MADRS and all other scales used in this study. Significantly associated variables from univariate analysis were entered into a multivariate (stepwise forward) linear regression analysis to build the model that predicts the outcome in the most accurate way. When using the dichotomized CSD, the influence of the predictors was studied using logistic regression. The van Elteren test, which is a particular form of the CochranMantel-Haenszel (CMH) test (Categorical Data Analysis Using the SAS System, SAS Institute, 2000; Cary, N.C., USA), was used to analyse the distribution of the mRS at 3 months after stroke with adjustment for baseline NIHSS scores. A value of $\mathrm{p}<0.05$ was considered significant. Where appropriate, results were given as mean values \pm standard deviation (SD).

\section{Results}

Prevalence of PSD and Use of Antidepressant Medication

Twenty-four percent $(24.2 \%)$ of the retained study population $(n=135)$ showed significant symptoms of depression before stroke onset. The prevalence of PSD at 3 months poststroke $(\mathrm{n}=135)$ was $28.1 \%$ (CSD) with a shift in occurrence of depression within the study population. No baseline data on depressive symptoms was available for 15 patients $(11.1 \%)$. Twenty-three percent $(23.1 \%)$ of the patients $(n=120)$ who were not depressed at baseline had significant depressive symptoms at follow-up according to the CSD $(n=21)$. Seven of these patients were using antidepressants at follow-up compared to 14 patients who were not using antidepressants 3 months poststroke. On the other hand, $51.7 \%$ of the participants who showed depressive symptoms at baseline, no longer presented with significant symptoms of depression $(n=15)$. Three of these patients were using antidepressant medication at followup. There was no significant difference in CSD total scores between baseline and follow-up.

\section{Demographic Data and Vascular Risk Factors}

Patient characteristics of the retained study population $(n=135)$ and dropouts $(n=32)$, vascular risk factors and scores on scales of stroke severity (NIHSS), disability (FIM), independence in ADL functions (BI), cognition (cognitive domain of the FIM), quality of life (SIS) and depression before stroke (CSD) are presented in table 1.

A history of cerebrovascular disease was more frequent in dropouts than in the remainder of the study population. Dropouts were significantly older and more physically disabled, had higher dependency for care and had more speech and language problems after stroke.

PSD Symptoms in Relation to Medical History and Stroke Characteristics (table 2)

Seven patients were diagnosed with 'relevant concomitant neurological conditions' including dementia $(n=3)$ and Parkinson's disease $(n=4)$. The prevalence of depression for patients with dementia (2/3) and Parkinson's disease (3/4) was high.

In view of lesion location, $43 \%$ of the patients displayed a left hemispheric stroke, whereas the lesion was located in the right hemisphere in $36.3 \%$. A minority of patients (8.1\%) suffered from a bilateral stroke. The majority (83.7\%) of strokes were caused by ischemia. Most of the strokes (57\%) involved the middle cerebral artery territory. Nearly all aphasic patients (88.9\%) suffered from a left hemispheric lesion. No significant relation was found between lesion location (lateralisation or arterial territory) and PSD. 
Table 1. Characteristics of study population including completers and dropouts at baseline

\begin{tabular}{|c|c|c|c|}
\hline Characteristics & $\begin{array}{l}\text { Retained study } \\
\text { population }(\mathrm{n}=135)\end{array}$ & $\begin{array}{l}\text { Dropouts } \\
(\mathrm{n}=32)\end{array}$ & $\begin{array}{l}\mathrm{p} \text { value for } \\
\text { heterogeneity }\end{array}$ \\
\hline \multicolumn{4}{|l|}{ Demographics ${ }^{1}$} \\
\hline \multicolumn{4}{|l|}{ Gender } \\
\hline Male/female & $81 / 54(60 / 40)$ & $16 / 16(50 / 50)$ & 0.303 \\
\hline Age, years ${ }^{2}$ & $70.1 \pm 12.8$ & $74.7 \pm 12.3$ & 0.019 \\
\hline \multicolumn{4}{|l|}{ Marital status } \\
\hline Married/living together & $93(68.9)$ & $17(53.1)$ & 0.091 \\
\hline Single/divorced/widowed & $42(31.1)$ & $15(46.9)$ & \\
\hline \multicolumn{4}{|l|}{ Education } \\
\hline Primary school or less & $54(40.0)$ & $15(46.9)$ & 0.478 \\
\hline Secondary school/high school/university & $81(60.0)$ & $17(53.1)$ & \\
\hline \multicolumn{4}{|l|}{ Work situation } \\
\hline Retired & $108(80.0)$ & $26(81.2)$ & 0.873 \\
\hline \multicolumn{4}{|l|}{ Medical history (prestroke) $)^{1}$} \\
\hline Cardiovascular disease & $72(53.3)$ & $18(56.3)$ & 0.766 \\
\hline Cerebrovascular disease & $30(22.2)$ & $13(40.6)$ & 0.032 \\
\hline Hypertension & $92(68.1)$ & $22(68.8)$ & 0.948 \\
\hline Hyperlipidaemia & $51(37.8)$ & $16(50.0)$ & 0.205 \\
\hline Diabetes & $22(16.3)$ & 7 (21.9) & 0.454 \\
\hline Other neurological conditions & $7(5.2)$ & $3(9.4)$ & 0.406 \\
\hline Depression & $27(20.0)$ & $10(31.3)$ & 0.168 \\
\hline Previous smoker & $31(23.0)$ & $8(26.7)$ & 0.666 \\
\hline Current smoker & $42(31.1)$ & $5(16.7)$ & 0.113 \\
\hline \multicolumn{4}{|l|}{ Alcohol consumption } \\
\hline Male ( $\geq 21 \mathrm{u} /$ week $) /$ female ( $\geq 14 \mathrm{u} /$ week $)$ & $13(9.6)$ & $3(10.0)$ & 1.000 \\
\hline \multicolumn{4}{|l|}{ Medication use baseline ${ }^{1}$} \\
\hline Hypnotics/sedatives/anxiolytics & $29(21.5)$ & $11(34.4)$ & 0.124 \\
\hline Antidepressants & $15(11.1)$ & $5(15.6)$ & 0.544 \\
\hline \multicolumn{4}{|l|}{ Stroke severity ${ }^{2}$} \\
\hline NIHSS & $6.1 \pm 6.0$ & $11.8 \pm 9.1$ & 0.003 \\
\hline \multicolumn{4}{|l|}{ Functional impairment ${ }^{2}$} \\
\hline \multicolumn{4}{|l|}{ FIM } \\
\hline Total & $90.2 \pm 35.4$ & $66.8 \pm 40.9$ & 0.002 \\
\hline Motor & $62.3 \pm 27.9$ & $43.5 \pm 31.1$ & 0.001 \\
\hline Cognitive & $28.0 \pm 9.6$ & $23.3 \pm 11.2$ & 0.018 \\
\hline \multicolumn{4}{|l|}{ Level of independence ${ }^{2}$} \\
\hline BI & $65.7 \pm 36.8$ & $39.5 \pm 41.1$ & 0.001 \\
\hline \multicolumn{4}{|l|}{ Neurocognitive outcome measure ${ }^{1}$} \\
\hline \multirow[t]{2}{*}{ Aphasia } & $\mathrm{n}=119$ & $\mathrm{n}=28$ & \\
\hline & $24(20.2)$ & $5(17.9)$ & 0.782 \\
\hline \multirow[t]{2}{*}{ Dysarthria } & $\mathrm{n}=118$ & $\mathrm{n}=27$ & \\
\hline & $45(38.1)$ & $16(59.3)$ & 0.045 \\
\hline \multirow[t]{2}{*}{ Apraxia } & $\mathrm{n}=112$ & $\mathrm{n}=24$ & \\
\hline & $21(18.8)$ & $5(20.8)$ & 0.780 \\
\hline Significant depressive symptoms prestroke ${ }^{1}$ & $\mathrm{n}=120$ & $\mathrm{n}=29$ & \\
\hline CSD & $29(24.2)$ & $6(20.7)$ & 0.692 \\
\hline Quality of life prestroke (SIS) ${ }^{2}$ & $\mathrm{n}=55$ & $\mathrm{n}=19$ & \\
\hline Total & $94.6 \pm 9.3$ & $92.8 \pm 9.9$ & 0.505 \\
\hline Mobility & $94.3 \pm 11.2$ & $88.2 \pm 16.3$ & 0.053 \\
\hline Memory & $97.6 \pm 10.6$ & $98.7 \pm 2.4$ & 0.313 \\
\hline Emotion & $89.5 \pm 10.3$ & $92.8 \pm 10.9$ & 0.099 \\
\hline Communication & $98.2 \pm 9.3$ & $99.6 \pm 1.6$ & 0.601 \\
\hline Activity & $95.2 \pm 13.1$ & $91.0 \pm 17.9$ & 0.579 \\
\hline
\end{tabular}

Data are given as means \pm SD or as numbers with percentages in parentheses, unless otherwise indicated.

${ }^{1} \chi^{2}$ or Fisher's exact test (with expected counts $<5$ ) for discontinuous variables was used. ${ }^{2}$ Student's $t$ test (independent) for continuous variables or the Mann-Whitney U rank sum test in case of a non-normal distribution or small numbers was used. $\mathrm{u}=$ Units. 
De Ryck et al.: A Prospective Study on the Prevalence and Risk Factors of Poststroke Depression

Table 2. Comparing depressive and non-depressive stroke patients 3 months poststroke

\begin{tabular}{|c|c|c|c|}
\hline Characteristics & $\begin{array}{l}\text { Depression } \\
(\mathrm{n}=38)\end{array}$ & $\begin{array}{l}\text { No depression } \\
(\mathrm{n}=97)\end{array}$ & $\begin{array}{l}\mathrm{p} \text { value of } \\
\text { difference }\end{array}$ \\
\hline \multicolumn{4}{|l|}{ Demographics ${ }^{1}$} \\
\hline \multicolumn{4}{|l|}{ Gender } \\
\hline Male/female & $18 / 20(47.4 / 52.6)$ & $63 / 34(64.9 / 35.1)$ & 0.061 \\
\hline Age, years ${ }^{2}$ & $72.8 \pm 11.0$ & $69.0 \pm 13.4$ & 0.232 \\
\hline \multicolumn{4}{|l|}{ Marital status } \\
\hline Single/divorced/widowed & $16(42.1)$ & $26(26.8)$ & 0.084 \\
\hline \multicolumn{4}{|l|}{ Education } \\
\hline No education/primary school & $19(50)$ & $35(36.1)$ & 0.138 \\
\hline \multicolumn{4}{|l|}{ Work situation } \\
\hline Retired & $34(89.5)$ & $74(76.3)$ & 0.085 \\
\hline \multicolumn{4}{|l|}{ Medical history (prestroke $)^{1}$} \\
\hline Cardiovascular disease & $23(60.5)$ & $49(50.5)$ & 0.294 \\
\hline Cerebrovascular disease & $9(23.7)$ & $21(21.6)$ & 0.798 \\
\hline Hypertension & $28(73.7)$ & $64(66)$ & 0.388 \\
\hline Hyperlipidaemia & $16(42.1)$ & $35(36.1)$ & 0.516 \\
\hline Diabetes & $5(13.2)$ & $17(17.5)$ & 0.537 \\
\hline Other neurological conditions & $5(13.2)$ & $2(2.1)$ & 0.019 \\
\hline Depression & $8(21.1)$ & $19(19.6)$ & 0.848 \\
\hline Smoking & $16(42.1)$ & $57(58.8)$ & 0.081 \\
\hline \multicolumn{4}{|l|}{ Alcohol consumption prior to stroke: } \\
\hline Male ( $\geq 21 \mathrm{u} /$ week $) /$ female $(\geq 14 \mathrm{u} /$ week $)$ & $3(7.9)$ & $10(10.3)$ & 1.000 \\
\hline \multicolumn{4}{|l|}{ Medication use baseline 1} \\
\hline Hypnotics/sedatives/anxiolytics & $13(34.2)$ & $16(16.5)$ & 0.024 \\
\hline Antidepressants & $2(5.3)$ & $13(13.4)$ & 0.232 \\
\hline \multicolumn{4}{|l|}{ Medication use follow-up ${ }^{1}$} \\
\hline Hypnotics/sedatives/anxiolytics & $11(28.9)$ & $20(20.6)$ & 0.301 \\
\hline Antidepressants & $10(26.3)$ & $22(22.7)$ & 0.655 \\
\hline Lesion location ${ }^{1}$ & $\mathrm{n}=32$ & $\mathrm{n}=86$ & \\
\hline Left hemispheric & $17(53.1)$ & $41(47.7)$ & 0.599 \\
\hline Right hemispheric & $14(43.8)$ & $35(40.7)$ & 0.765 \\
\hline Bilateral & $1(3.1)$ & $10(11.6)$ & 0.285 \\
\hline \multicolumn{4}{|l|}{ Left } \\
\hline $\mathrm{ACA}$ & $0(0)$ & $1(1.2)$ & 1.000 \\
\hline MCA & $13(40.6)$ & $24(27.9)$ & 0.186 \\
\hline PCA & $1(3.1)$ & $6(7.0)$ & 0.672 \\
\hline Vertebrobasilar artery & $2(6.3)$ & $4(4.7)$ & 0.662 \\
\hline \multicolumn{4}{|l|}{ Right } \\
\hline $\mathrm{ACA}$ & $0(0)$ & $1(1.2)$ & 1.000 \\
\hline MCA & $10(31.3)$ & $25(29.1)$ & 0.818 \\
\hline PCA & $1(3.1)$ & $3(3.5)$ & 1.000 \\
\hline Vertebrobasilar artery & $3(9.4)$ & $1(1.2)$ & 0.060 \\
\hline \multicolumn{4}{|l|}{ Functional impairment ${ }^{2}$} \\
\hline \multicolumn{4}{|l|}{ FIM } \\
\hline Total & $94.7 \pm 33,4$ & $115.7 \pm 18.3$ & $<0.001$ \\
\hline Motor & $67.4 \pm 25.3$ & $83.2 \pm 14.7$ & $<0.001$ \\
\hline Cognitive & $27.4 \pm 9.3$ & $32.5 \pm 5.3$ & $<0.001$ \\
\hline \multicolumn{4}{|l|}{ Level of independence $^{2}$} \\
\hline BI & $73.6 \pm 34.4$ & $92.4 \pm 18.1$ & $<0.001$ \\
\hline \multicolumn{4}{|l|}{ Cognitive screening $^{2}$} \\
\hline MMSE & $25.1 \pm 4.6$ & $27.1 \pm 3.9$ & 0.015 \\
\hline
\end{tabular}


Table 2 (continued)

\begin{tabular}{lllr}
\hline Characteristics & $\begin{array}{l}\text { Depression } \\
(\mathrm{n}=38)\end{array}$ & $\begin{array}{l}\text { No depression } \\
(\mathrm{n}=97)\end{array}$ & $\begin{array}{r}\text { p value of } \\
\text { difference }\end{array}$ \\
\hline $\begin{array}{l}\text { Neurocognitive outcome measure } \\
\text { Speech and language impairment }\end{array}$ & $14(36.8)$ & $19(19.6)$ & 0.036 \\
Apraxia & $\mathrm{n}=35$ & $\mathrm{n}=97$ & \\
& $12(34.3)$ & $12(12.4)$ & 0.004 \\
\hline Stroke impact (SIS) & $\mathrm{n}=38$ & $\mathrm{n}=96$ & \\
Total & $62.9 \pm 25.7$ & $85.7 \pm 14.5$ & $<0.001$ \\
Mobility & $59.3 \pm 32.0$ & $84.8 \pm 20.5$ & $<0.001$ \\
Memory & $65.6 \pm 34.7$ & $91.0 \pm 16.1$ & $<0.001$ \\
Emotion & $67.2 \pm 14.3$ & $88.5 \pm 10.7$ & $<0.001$ \\
Communication & $78.0 \pm 32.1$ & $91.9 \pm 18.5$ & 0.006 \\
Activity & $49.6 \pm 32.0$ & $74.0 \pm 24.0$ & $<0.001$ \\
\% Recovery & $57.2 \pm 31.0$ & $79.2 \pm 19.6$ & 0.001 \\
\hline
\end{tabular}

Data are given as means \pm SD or as numbers with percentages in parentheses, unless otherwise indicated. $\mathrm{u}=$ Units.

${ }^{1} \chi^{2}$ or Fisher's exact test (with expected counts $<5$ ) for discontinuous variables was used. ${ }^{2}$ Student's $t$ test (independent) for continuous variables or the Mann-Whitney $U$ rank sum test in case of a non-normal distribution or small numbers was used.

Table 3. Regression analysis of potential risk factors for developing PSD $(n=135)$

\begin{tabular}{|c|c|c|c|c|}
\hline & \multicolumn{2}{|l|}{ CSD } & \multicolumn{2}{|c|}{ MADRS } \\
\hline & $\rho$ & $\begin{array}{l}\mathrm{p} \text { value } \\
\text { (linear regression) }\end{array}$ & $\rho$ & $\begin{array}{l}\mathrm{p} \text { value } \\
\text { (linear regression) }\end{array}$ \\
\hline \multicolumn{5}{|l|}{ Stroke severity } \\
\hline NIHSS & 0.245 & 0.009 & 0.376 & $<0.001$ \\
\hline \multicolumn{5}{|l|}{ Stroke outcome } \\
\hline $\mathrm{mRS}$ & 0.419 & $<0.001$ & 0.473 & $<0.001$ \\
\hline \multicolumn{5}{|l|}{ Level of independence } \\
\hline $\mathrm{BI}$ & -0.426 & $<0.001$ & -0.487 & $<0.001$ \\
\hline \multicolumn{5}{|c|}{ Functional impairment } \\
\hline FIM total & -0.442 & $<0.001$ & -0.491 & $<0.001$ \\
\hline FIM motor & -0.406 & $<0.001$ & -0.439 & $<0.001$ \\
\hline FIM cognitive & -0.383 & $<0.001$ & -0.447 & $<0.001$ \\
\hline \multicolumn{5}{|l|}{ Cognitive screening } \\
\hline MMSE & -0.335 & 0.009 & -0.361 & $<0.001$ \\
\hline \multicolumn{5}{|l|}{ Stroke Impact Scale } \\
\hline Total & -0.584 & $<0.001$ & -0.608 & $<0.001$ \\
\hline Mobility & -0.452 & $<0.001$ & -0.453 & $<0.001$ \\
\hline Memory & -0.500 & $<0.001$ & -0.542 & $<0.001$ \\
\hline Emotions & -0.713 & $<0.001$ & -0.772 & $<0.001$ \\
\hline Communication & -0.310 & $<0.001$ & -0.340 & $<0.001$ \\
\hline Activity & -0.459 & $<0.001$ & -0.466 & $<0.001$ \\
\hline
\end{tabular}




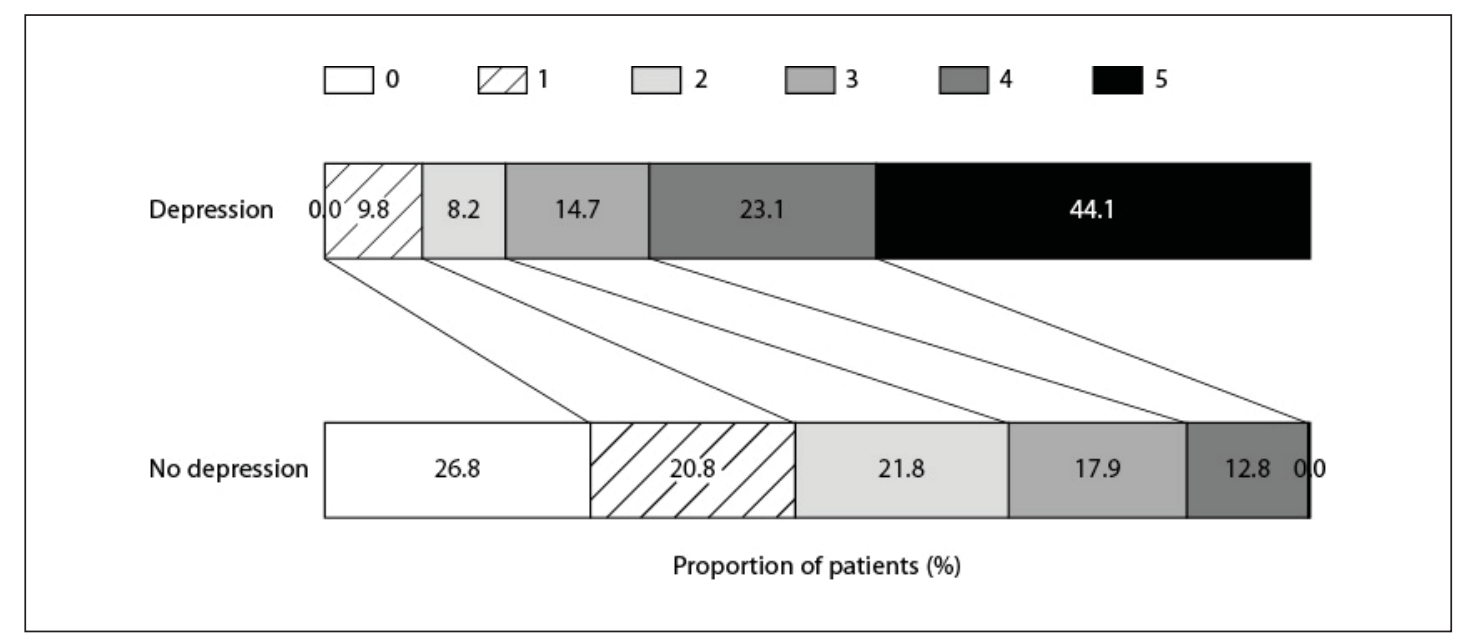

Fig. 2. Distribution of the mRS scores at 3 months after stroke for patients with depression and patients without depression (CMH test; $\mathrm{p}<0.001)$.

PSD Symptoms in Relation to Functional and Cognitive Deficits (table 2)

As compared to patients without depression at follow-up, patients with PSD were significantly more dependent in ADL functions and had more severe physical impairment as assessed by the BI, mRS, FIM and the SIS and were more cognitively impaired as measured by the MMSE and cognitive domains of FIM and SIS.

The distribution of $\mathrm{mRS}$ scores differed significantly comparing both groups $(\mathrm{p}<0.001$ by the $\mathrm{CMH}$ test) as patients with depression displayed markedly higher mRS scores (fig. 2).

Almost 37\% of the patients with PSD had speech and language problems compared to $19.6 \%$ of non-depressed patients $(\mathrm{p}=0.036)$. Of these non-depressed patients $(\mathrm{n}=19), 7$ used antidepressants 3 months poststroke. Furthermore, apraxia occurred more frequently in PSD than in non-depressed patients (34.3 vs. $12.4 \%$; $\mathrm{p}=0.004)$.

\section{Risk Factors}

Potential risk factors for developing PSD were analysed by correlation and univariate linear regression analysis, using CSD and MADRS as dependent variables. Significant associations were identified between PSD and stroke severity (NIHSS), long-term outcome (mRS), level of independence (BI), functional impairment (FIM), general cognition (MMSE) and reduced quality of life (SIS). p values for the Spearman rank correlation coefficients and linear regression analysis are shown in table 3.

Stepwise forward multiple linear regression, including all predictors analysed in the univariate analyses, generated a prediction model including cognitive impairment and reduced mobility as part of the SIS as the only significant predictors for significant depressive symptoms based on CSD, accounting for $26.9 \%$ of the variance. Including the same two predictors in a final model based on the MADRS, the explained variance $\left(\mathrm{r}^{2}\right)$ was $47.4 \%$.

In addition, to further model the risk for depression based upon the risk factors, we used the dichotomized CSD as outcome variable in logistic regression analysis. Stepwise forward regression using all previously listed risk factors as input showed that only cognitive impairment as part of the SIS remained as a significant predictor for the risk for depression. This showed that for one-unit increase in improvement of cognition, the risk for depression decreases multiplicatively by approximately $5 \%$. 


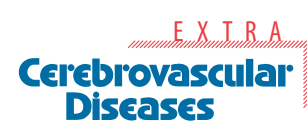

Diseases
Cerebrovasc Dis Extra 2013;3:1-13

DOI: 10.1159/000345557

Published online: January 26, 2013

De Ryck et

Depression

\section{Discussion}

Numerous studies investigated prevalence and risk factors for PSD but variable results were reported depending on populations, assessment measures and definition of depression used $[2,3]$. The prevalence of PSD in this study at 3 months poststroke was $28.1 \%$, which is both lower [22] and higher [23] than previously reported. Compared to completers, dropouts were more physically disabled, more care dependent and displayed more speech and language problems. According to the existing literature and our own findings [22, 24-26], these variables were risk factors for PSD, which might explain lower prevalence of PSD in the retained study population.

No significant differences were found between depressed and non-depressed patients at 3 months poststroke with regard to gender, age, education and living conditions (alone or with someone else). Living alone has been reported to be associated with an increased risk of PSD in some studies [27] but not in others [3,28]. Women had higher scores on CSD and MADRS than men but this difference was not statistically significant.

A history of depression was reported to be associated with PSD [27, 29], which was not observed in the present study. Nearly $52 \%$ percent (51.7\%) of the participants who showed depressive symptoms at baseline, no longer presented significant depressive symptoms at follow-up. Three patients who no longer presented significant depressive symptoms were using antidepressant medication. Fourteen patients showed depressive symptoms at baseline and continued to have depressive symptoms at follow-up. Most of them (78.6\%) were not using antidepressants at follow-up. Additionally, 14 patients who showed depressive symptoms at follow-up but not at baseline were also not using antidepressants, which might reflect underdiagnosis of significant depressive symptoms.

In literature, controversy exists on the possible association between PSD and left hemispheric stroke. In line with others, our results do not support a relation between left hemispheric stroke and risk of PSD [28, 30].

Consistent with previous reports, patients with PSD were more dependent with regard to ADL functions, more physically and cognitively impaired and had less quality of life as measured by the SIS $[31,32]$.

Merits of this single centre prospective Belgian study are the highly standardised evaluation of stroke patients and inclusion of patients with aphasia and cognitive impairment. The study design enables us to study risk factors of PSD in the different phases after stroke. Moreover, patient assessments were performed by trained interviewers using internationally accepted and validated scales for stroke severity, functional outcome, cognitive deficits and depressive symptoms. The inclusion of people with aphasia offers an added value, since stroke patients with aphasia were mostly excluded from other studies. Aphasia is common after stroke and results in a sudden dysfunction in many activities of daily life [33], and has been established as an important risk factor for depression [22]. Using the CSD, which can be used for completion through observation and an interview of a relative, simplified the survey of this specific group of patients. Additionally, patients will be evaluated up to 18 months poststroke, which will allow us to observe risk factors for PSD from the acute phase over the convalescent phase up to the chronic phase of stroke.

The findings of our study add to the already vast literature on significant depressive symptoms in stroke patients, and further validate the multifactorial nature of PSD and its association with reduced compliance with therapy including rehabilitation and unfavourable outcome.

A potential limitation of this study is the non-psychiatric assessment of depression. However, occurrence of depressive symptoms was assessed by means of the MADRS, a reliable observer-rated measure, whereas a formal psychiatric assessment might not be feasible 
in all clinical settings or in patients with cognitive deficits or aphasia. Moreover, the MADRS has often been used in stroke patients [34] and puts little emphasis on somatic symptoms. This is important because some of the symptoms that are used to diagnose depression such as fatigue, pain, or sleeping disorders can result of stroke [35]. Given that these somatic symptoms are common in the first weeks of stroke, we avoided standard self-rating questionnaires or standard criteria. In the present study, the CSD completed through observation and informant-based questions with a relative has proved his usefulness in stroke patients with aphasia, cognitive impairment, confusion and/or reduced consciousness due to stroke.

As 32 dropouts were mostly patients with more severe strokes, more severe functional impairment and a lower level of independence at baseline as shown in table 1, we cannot rule out that PSD contributed to the fact that 16 patients did not show up at their follow-up visit which is a limitation of the study as this might have introduced a bias.

The use of antidepressants at 3 months poststroke (23.7\%) was significantly more frequent than at baseline and might as well be related to the lower prevalence of PSD in our study. The use of antidepressant medication can be a confounding factor as 14 patients without significant depressive symptoms at baseline and follow-up were taking antidepressants at follow-up. Six patients were using antidepressant medication prior to stroke. The use of antidepressants might have led to an improvement of depressive symptoms and consequently to a lower prevalence of PSD at 3 months poststroke.

In conclusion, functional and cognitive impairment, a greater dependency with regard to ADL functions, speech and language problems, apraxia and an overall lower quality of life after stroke are associated with increased incidence of poststroke depressive symptoms in the convalescent phase. All these variables are correlated, but multiple regression models indicated that the most determining features for depression risk in the convalescent phase include reduced mobility and cognitive impairment.

Further studies on risk factors for PSD are essential, given its negative impact on rehabilitation, functional outcome and quality of life. Identification of risk factors for PSD may allow more efficacious preventive measures and early implementation of adequate antidepressive treatment.

\section{Acknowledgements}

The research described in this paper was funded in part by the Interuniversity Attraction Poles program P7/16 of the Belgian Science Policy Office, the Methusalem excellence program of the Flemish Government, the Research Foundation Flanders (FWO), Neurosearch Antwerp, the Special Research Fund of the University of Antwerp, and the Institute Born-Bunge, Antwerp, Belgium.

\section{References}

1 Hacke W: European Stroke Initiative Recommendations for Stroke Management - Update 2003. Cerebrovasc Dis 2003;16:311-337.

-2 Naess H, Nyland HI, Thomassen L, Aarseth J, Myhr KM: Mild depression in young adults with cerebral infarction at long-term follow-up: a population-based study. Eur J Neurol 2005;12:194198.

-3 Kotila M, Numminen H, Waltimo O, Kaste M: Post-stroke depression and functional recovery in a population-based stroke register. The Finnstroke study. Eur J Neurol 1999;6:309-312. 
-4 Williams LS, Ghose SS, Swindle RW: Depression and other mental health diagnoses increase mortality risk after ischemic stroke. Am J Psychiat 2004;161:1090-1095.

-5 Wolfe CD: The impact of stroke. Br Med Bull 2000;56:275-286.

-6 Gainotti G, Antonucci G, Marra C, Paolucci S: Relation between depression after stroke, antidepressant therapy, and functional recovery. J Neurol Neurosurg Psychiatry 2001;71:258-261.

-7 Sturm JW, Donnan GA, Dewey HM, Macdonell RA, Gilligan AK, Srikanth V, et al: Quality of life after stroke - The North East Melbourne Stroke Incidence Study (NEMESIS). Stroke 2004;35:23402345.

-8 Whyte EM, Mulsant BH: Post stroke depression: epidemiology, pathophysiology, and biological treatment. Biol Psychiat 2002;52:253-264.

-9 Anderson RJ, Freedland KE, Clouse RE, Lustman PJ: The prevalence of comorbid depression in adults with diabetes. Diabetes Care 2001;24:1069-1078.

10 Hacket ML, Anderson CS: Predictors of depression after stroke: a systematic review of observational studies. Stroke 2005;36:2296-2301.

-11 Gebruers N, Truijen S, Engelborghs S, Nagels G, Brouns R, De Deyn PP: Actigraphic measurement of motor deficits in acute ischemic stroke. Cerebrovasc Dis 2008;26:533-540.

-12 Brouns R, Heylen E, Willemse JL, Sheorajpanday R, De Surgeloose D, Verkerk R, et al: The decrease in procarboxypeptidase U (TAFI) concentration in acute ischemic stroke correlates with stroke severity, evolution and outcome. J Thromb Haemost 2010;8:75-80.

13 Albers GW, Caplan LR, Easton JD, Fayad PB, Mohr JP, Saver JL, et al: Transient ischemic attack proposal for a new definition. New Engl J Med 2002;347:1713-1716.

- 14 Brott T, Adams HP Jr, Olinger CP, Marler JR, Barsan WG, Biller J, et al: Measurements of acute cerebral infarction: a clinical examination scale. Stroke 1989;20:864-870.

15 Dromerick AW, Edwards DF, Diringer MN: Sensitivity to changes in disability after stroke: a comparison of four scales useful in clinical trials. J Rehabil Res Dev 2003;40:1-8.

-16 Mahoney FI, Barthel DW: Functional evaluation: the Barthel Index. Maryland State Med J 1965;14: 61-65.

17 Duncan PW, Jorgensen HS, Wade DT: Outcome measures in acute stroke trials - a systematic review and some recommendations to improve practice. Stroke 2000;31:1429-1438.

-18 Folstein MF, Maiberger R, McHugh PR: Mood disorder as a specific complication of stroke. J Neurol Neurosurg Psychiatry 1977;40:1018-1020.

-19 Duncan PW, Lai SM, Tyler D, Perera S, Reker DM, Studenski S: Evaluation of proxy responses to the Stroke Impact Scale. Stroke 2002;33:2593-2599.

-20 Alexopoulos GS, Abrams RC, Young RC, Shamoian CA: Cornell scale for depression in dementia. Biol Psychiat 1988;23:271-284.

-21 Montgomery SA, Åsberg M: New Depression Scale Designed to be Sensitive to Change. Brit J Psychiat 1979;134:382-389.

-22 Carota A, Berney A, Aybek S, Iaria G, Staub F, Ghika-Schmid F, et al: A prospective study of predictors of poststroke depression. Neurology 2005;64:428-433.

-23 Snaphaan L, van der Werf S, Kanselaar K, de Leeuw FE: Post-stroke depressive symptoms are associated with post-stroke characteristics. Cerebrovasc Dis 2009;28:551-557.

-24 Burvill P, Johnson G, Jamrozik K, Anderson C, Stewart-Wynne E: Risk factors for post-stroke depression. Int J Geriatr Psych 1997;12:219-226.

-25 Kotila M, Numminen H, Waltimo O, Kaste M: Depression after stroke: results of the FINNSTROKE Study. Stroke 1998;29:368-372.

-26 Whyte EM, Mulsant BH, Vanderbilt J, Dodge HH, Ganguli M: Depression after stroke: a prospective epidemiological study. J Am Geriatr Soc 2004;52:774-778.

-27 Andersen G, Vestergaard K, Ingemannnielsen M, Lauritzen L: Risk factors for post-stroke depression. Acta Psychiat Scand 1995;92:193-198.

28 Berg A, Palomaki H, Lehtihalmes M, Lonnqvist J, Kaste M: Poststroke depression: an 18-month follow-up. Stroke 2003,34:138-143.

29 Paolucci S, Gandolfo C, Provinciali L, Torta R, Sommacal S, Toso V: Quantification of the risk of poststroke depression: the Italian multicenter observational study DESTRO. Acta Psychiat Scand 2005;112:272-278. 
De Ryck et al.: A Prospective Study on the Prevalence and Risk Factors of Poststroke Depression

- 30 Carson AJ, MacHale S, Allen K, Lawrie SM, Dennis M, House A, et al: Depression after stroke and lesion location: a systematic review. Lancet 2000;356:122-126.

- 31 Berg A, Palomaki H, Lehtihalmes M, Lonnqvist J, Kaste M: Poststroke depression in acute phase after stroke. Cerebrovasc Dis 2001;12:14-20.

-32 Kauhanen ML, Korpelainen JT, Hiltunen P, Nieminen P, Sotaniemi KA, Myllylä VV: Domains and determinants of quality of life after stroke caused by brain infarction. Arch Phys Med Rehabil 2000; 81:1541-1546.

-33 Thomas SA, Lincoln NB: Predictors of emotional distress after stroke. Stroke 2008;39:1240-1245.

- 34 Singh A, Black SE, Herrmann N, Leibovitch FS, Ebert PL, Lawrence J, et al: Functional and neuroanatomic correlations in poststroke depression: the Sunnybrook Stroke Study. Stroke 2000;31:637644.

- 35 Gainotti G, Azzoni A, Razzano C, Lanzillotta M, Marra C, Gasparini F: The Post-Stroke Depression Rating Scale: a test specifically devised to investigate affective disorders of stroke patients. J Clin Exp Neuropsychol 1997;19:340-356. 